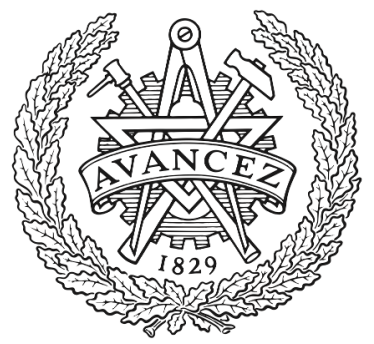

CHALMERS

UNIVERSITY OF TECHNOLOGY

\title{
Lost in translation: A framework for analysing complexity of co-production settings in relation to epistemic communities, linguistic diversities and
}

Downloaded from: https://research.chalmers.se, 2023-04-26 12:43 UTC

Citation for the original published paper (version of record):

Nikulina, V., Larson Lindal, J., Baumann, H. et al (2019). Lost in translation: A framework for analysing complexity of co-production settings in relation to epistemic communities, linguistic diversities and culture. Futures, 113.

http://dx.doi.org/10.1016/j.futures.2019.102442

N.B. When citing this work, cite the original published paper. 


\title{
Lost in translation: A framework for analysing complexity of co- production settings in relation to epistemic communities, linguistic diversities and culture
}

\author{
Varvara Nikulina $^{\mathrm{a}, \mathrm{d}, *}$, Johan Larson Lindal ${ }^{\mathrm{b}}$, Henrikke Baumann ${ }^{\mathrm{c}}$, David Simon ${ }^{\mathrm{d}}$, \\ Henrik $\mathrm{Ny}^{\mathrm{a}}$ \\ ${ }^{a}$ Department of Strategic Sustainable Development, Blekinge Institute of Technology, SE-37179, Karlskrona, Sweden \\ ${ }^{\mathrm{b}}$ Mistra Urban Futures Stockholm Node project (SNOD), OpenLab, Valhallavägen 79, SE-11427, Stockholm, Sweden \\ ${ }^{\mathrm{c}}$ Department of Environmental Systems Analysis, Chalmers University of Technology, Vera Sandbergs allé 8, SE-41296, Gothenburg, Sweden \\ ${ }^{\mathrm{d}}$ Mistra Urban Futures, Chalmers University of Technology, SE-41296, Gothenburg, Sweden
}

\section{A R T I C L E I N F O}

\section{Keywords:}

Transdisciplinary

Linguistic diversity

Multicultural

Epistemic communities

Multi-stakeholder dialogue

Urban planning

\begin{abstract}
A B S T R A C T
Planning in modern urban environments requires skills to address complexity in order to move towards sustainability. Co-production of knowledge in transdisciplinary groups represents a useful tool in such contexts. Using the concepts of epistemic communities, linguistic diversity and culture, the article proposes a conceptual framework for analysing complexity of co-production settings, as an indispensable means of managing complex challenges, thus making these complexities visible for the project leader (facilitator) and the participants of the co-production process. We evaluate the framework on the basis of inclusivity, cross-sectoral understanding, applicability in different contexts and time perspectives. Based on the framework, we identify several aspects that a process leader (facilitator) would need to address when preparing for a coproduction process: linguistic equality between participants, disciplinary integrity, a working culture of mutual respect, simultaneous mitigation and informed facilitation. Finally, the article suggests possible future research areas related to development of the framework, including (i) identification of levels of complexity and mapping specific tools to address complexity at each level; (ii) integration of other factors of complexity, such as political and institutional contexts, as well as diversity of gender and age in the facilitated group.
\end{abstract}

\section{Introduction}

The metaphor 'lost in translation' can be understood in three ways. It applies not only in literal terms - message being lost due to language constructions - but also for transdisciplinary spaces where the languages of different epistemic communities of practice (networks of experts that share a common knowledge-base) (Haas, 1992) become a barrier. The third underlying angle of being 'lost in translation' is the aspect of culture that cannot easily be depicted in words but still plays a crucial role in interpersonal communication of co-production processes. These three aspects therefore also take part in shaping the experience of such processes.

Managing complex problems in complex adaptive systems, such as urban planning with the objective of sustainable development, requires both a reductionist (disciplinary and specialized knowledge) and a systemic (transdisciplinary and co-produced knowledge)

\footnotetext{
*Corresponding author at: Department of Strategic Sustainable Development, Blekinge Institute of Technology, SE-37179, Karlskrona, Sweden. E-mail address: varvara.nikulina@bth.se (V. Nikulina).
} 
perspective (Brouwer, Woodhill, Hemmati, Verhoosel, \& van Vugt, 2016, p. 46). As the factors affecting sustainable urban development are too many to be managed simultaneously by one transdisciplinary process, framing the challenge and prioritizing key efforts is essential to the effectiveness with which the process is managed (Wuelser, Pohl, \& Hirsch Hadorn, 2012, p. 82). However, being itself part of the complex adaptive system which it attempts to affect, the transdisciplinary process faces challenges of complexity as well.

The common denominator for the chosen concepts of epistemic communities, linguistic diversities and culture which constitute part of complexity in the given context, is their fundamental importance concerning boundaries of meaning (see for example Benveniste, 1971), communication (see for example Mills, 1997) and recognition (Honneth, 1992; see also Section 3.2). Ultimately, they concern mutual understanding in relation to diversity between stakeholders both on an individual level and between different collectives, but also between individuals within a larger group of collaborating collectives. Aiming for mutual understanding while preserving diversity is considered a prerequisite as well as a challenge for joint production of knowledge (Pohl et al., 2010). Epistemic communities, a diversity of languages, and culture, however, all comprise obstacles to mutual understanding, regardless of other conditions affecting participants in joint knowledge production (such as material inequalities and different schedules). Moreover, epistemic communities, language and culture are closely interrelated and affect one another constantly. Different thought styles through the interpretation and use of concepts exist even within the same language but are usually more pronounced between languages (Haas, 1992). In the context of multiple languages, participants in a transdisciplinary process are exposed to even more potential ambiguities and misunderstandings (Weber, 2018). Furthermore, epistemic communities and linguistic diversity are affected by the cultures of the particular organizational and working environments to which participants of transdisciplinary urban planning processes belong, as well as the combination of individual participants' cultural background regardless of their employment (Somerville, 2005).

\subsection{Epistemic communities}

Modern cities face increasing complexity in relation to planning necessary to address the imperative of moving towards sustainability. Our society's present capacity to do so is inadequate (Brown, 2008). This challenge is relevant in local, national and international contexts, meaning that policymakers are in ever greater need of expert knowledge to be able to make well-informed choices. Experts are now found in diverse areas within and outside of academia. Their joint efforts are necessary to tackle such complex challenges, as exemplified by co-production of knowledge in transdisciplinary groups (Polk \& Kain, 2015). These groups are represented by a range of epistemic communities (Haas, 1992). In Western tradition, specialised knowledge became a barrier for social learning necessary to address complexity (Brown, 2008). This also affected non-Western countries whose local knowledge has become inaccessible through the increasing dominance of Western discourses and technologies (Simon, Palmer, Riise, Smit, \& Valencia, 2018). In transdisciplinary teams, challenges of knowledge diversity are accelerated for a number of reasons such as different contexts within and between regions of the world; less shared epistemological understanding or theory of knowledge (Creswell \& Poth, 2018); power relations between diverse actors and societal sectors, and culture in terms of practice, traditions, values and norms (Simon et al., 2018). The challenges of unequal dispositions and power relations in co-producing knowledge are evident and need to be managed if the outcomes are to match the purpose of combining diverse expertise. As a starting point, one discipline must not be favoured over another (Pohl et al., 2010).

Being part of the same epistemic communities is argued to support a dialogue in transdisciplinary co-production of knowledge through a shared systemic view of the challenge, enabling the identification of local needs, the framing of debate and negotiation, and, finally, the identification of suitable solutions and policies (Simon, McGregor, Nsiah-Gyabaah, \& Thompson, 2003). At the same time, local context can play a key role in co-production processes as even within the same epistemic community, challenges may arise if other variables separate participants.

The level of complexity in transdisciplinary planning is severely increased when language barriers are present. Still, English is generally used as the everyday language as if virtually unproblematic, although it is certainly acknowledged that language is intimately linked to relations of power. This challenge has recently been highlighted by the German linguist Tilo Weber as a major obstacle for equal participation in transdisciplinary processes (Weber, 2018).

\subsection{Linguistic diversity}

Linguistic diversity (a concentration of unique languages in one context) is a widespread phenomenon in many contemporary states and urban areas. Canada, for example, has a long experience of mitigating the linguistic differences between French and English speaking citizens (Sullivan, 2004, p. 991). Sweden also has five official minority languages, Finnish, Jiddisch, Romani, Meänkieli and Sámi, each with its own historical legacy and legislative protection as well as some guaranteed administrative support to its speakers (Sundberg, 2013). Kenya has two official languages - English and Swahili, however there are many local languages and dialects, and even within the same city it is difficult to facilitate a dialogue (Nikulina, Baumann, Simon, \& Sprei, 2018). One can also find many other examples of such contexts around the world.

Today, the need for multilingual dialogue is greater than ever. Different linguistic communities within the same region or stakeholders from regions in different countries need to co-operate in order to tackle complex societal problems, the UN and the EU 
being major examples of a much wider and everyday-based development. For example, the Sustainable Development Goals ${ }^{1}$ invite nations to collaborate in addressing a number of challenges formulated as goals. The challenges and possibilities of multilingual dialogue are essential elements in an era of globalization, multicultural societies and linguistic pluralism. Linguistic diversity is influenced and challenged by a still widespread universalist ideology of one common language (or lingua franca) claiming lingua franca as a prerequisite for maintaining vivid democratic dialogue (Lüdi, 2015, p. 214). This is accompanied by increasing provincialism and nationalism throughout the world while the need for co-producing solutions to complex societal challenges within and across nation-borders is evident.

Georges Lüdi (2015, p. 215) says:

"The steady increase in the numbers of migrants, expatriates, exchange of scientists, etc. and the globalisation of communication through electronic media entail many forms of social multilingualism at the workplace, i.e. people with very different linguistic and cultural background are brought to work together in mixed teams".

Taking into account the challenges described above, solving issues across different scales will require both local and general expertise, which entails encountering both linguistic and epistemic differences (Haas, 1992, pp. 12-13).

\subsection{Culture}

Working in a shared space of co-production in multi-stakeholder transdisciplinary groups can lead to a culture shock: entering a group different from yourself (Leslie \& Storey, 2003, pp. 122-127), where, based on personal and working culture, a new group culture should emerge in the process. While personal culture is often subdued, working culture can become a barrier, for example, when certain stakeholders are not accustomed to participatory approaches and feel uncomfortable openly sharing their opinions and thoughts. Cultural awareness both on a personal and on a working level becomes another condition for creating an inclusive environment for the participants in the dialogue (Brouwer et al., 2016; Simon et al., 2003).

\subsection{Aim and target audience}

The three concepts epistemic communities, linguistic diversity and culture that form the focus of this article are not novelties and they are used separately by different scholars and practitioners. Based on the literature review, we could not find effective frameworks that support the process of simultaneously managing these concepts. This risks creating major obstacles for bringing matters forward in some of the most complex and pressing contemporary and future problems and thereby it also risks not creating sufficiently well-informed decisions in ongoing change processes. Therefore, the aim of this paper is to present a framework for analysing complexity of co-production settings in relation to epistemic communities, linguistic diversities and culture, thus making their diversities visible to the project leader (facilitator) and the participants of the co-production process.

The paper is mainly intended for facilitators, itself a diverse and ambiguous group (Mackewn, 2008). Facilitators here refer to professionals taking on the role of guiding diverse working groups, such as the cases of multicultural, linguistically diverse transdisciplinary urban planning groups observed here. Providing facilitators with developed frameworks for such settings enables them to exercise their role and skills in a more productive way.

\section{Methodology}

In order to improve the ways for dealing with the challenges of understanding each other in co-production settings, a multidimensional framework that enables the analysis of translational, epistemic and cultural problems was developed.

\subsection{Framework development}

In order to develop a framework, we first undertook a literature review of three concepts that contribute to complexity, namely epistemic communities, linguistic diversity and culture and then synthesised the findings. The theoretical reasoning behind the choice of these three dimensions was outlined in Section 1. Another reason for choosing these particular concepts contributing to complexity arises from the experience of designing the three workshops (described in Section 4.1) and from reflecting on the previous experiences with facilitation of transdisciplinary groups in similar contexts. The results are outlined in Section 3.

\subsection{Application of the framework}

The developed framework was tested in three geographical locations across the South Baltic area. There, multi-stakeholder workshops for sustainable public transport were observed (see Section 4 for more details) and followed by interviews with the local table leaders (people who were managing small group discussions, often in their mother tongue). A list of four interviewees that were selected since their input was the most insightful can be found in the Table A1 (see Appendix A).

Observation enables systematic documentation of events in a chosen context (Agar, 1996; Scheyvens, 2014). It creates a "textual

\footnotetext{
${ }^{1}$ See: https://sustainabledevelopment.un.org
} 
picture" of the situation. For this specific study, the observer as participant stance was selected (Kawulich, 2005). It means that the observer can take part in the event, but priority in the process is given to the observation. During the workshops described below, the role of observer was combined with the role of facilitator. The limitations of this approach can be seen in researcher bias (Kawulich, 2005). As suggested in the literature, the reflexivity approach (May \& Perry, 2017) was used to reflect upon the observations. Moreover, a set of short interviews with table leaders was conducted shortly after the events.

For the purpose of this study, semi-structured interviews were used (Agar, 1996; Flowerdew \& Martin, 2005; Mikkelsen, 2005). In the qualitative interviews with the table leaders, the main themes were predetermined, whereas specific questions were raised in the process. The advantage of this approach was that an interviewee could lead the discussion and reveal information that might not have been foreseen by the interviewer.

The proposed framework was used to evaluate the transdisciplinary co-production processes in relation to epistemic communities, linguistic diversity and culture in the given contexts.

\subsection{Evaluation of the framework}

After its application tests in the workshops, the framework was evaluated in relation to inclusiveness of co-production processes, cross-sectoral understanding, applicability in different contexts and time perspective, which constitute some of the main aspects of the co-production approach (see Section 5.1).

\section{Framework development}

The framework that is proposed below is based on previous research and practical experience, and takes its origins in the literature related to epistemic communities, linguistic diversity and culture. These concepts are therefore described below.

\subsection{Epistemic communities}

Epistemic communities (Haas, 1992), or thought collectives (Fleck, Trenn, Merton, \& Bradley, 1979), are to be understood as groups with shared and agreed forms of knowledge, thought styles, differing from or even fundamentally opposing those of other groups. Examples are engineers vis-á-vis social scientists in academia and public servants vis-á-vis entrepreneurs in other societal sectors. Due to various contextual, historical and contemporary reasons, these groups share specific knowledge often difficult to integrate into other fields. Moreover, members of the same epistemic community spread around the world often work together more effectively than people of different epistemic communities living or working in the same locality (Simon et al., 2003). When successfully integrated, however, co-production of knowledge through collaborating thought collectives provides a more balanced understanding of a specific complex problem in the local context and its solutions, while also enabling more integrated research (Baumann, 2009; Haas, 1992; Pohl et al., 2010).

Even within the same epistemic community, challenges may arise and change according to local context (Simon et al., 2018). No single thought style is able to derive the same results and knowledge everywhere, especially from a global perspective, as stated by James Esson and his colleagues (2016, p. 40) in a study of Accra's mobility systems:

"The overarching argument that emerges from bringing a holistic approach that combines transport, mobility and livelihoods into conversation with the empirical findings is that conceptual frameworks such as the new mobility paradigm derived entirely based on conditions in the global North, are inherently limited, despite their implicit claims of global relevance".

\subsection{Linguistic diversity}

Sue Wright (2011) has argued for a lingua franca - that is English - in order to promote equal opportunity to evaluate information and make judgements and decisions in a European democratic context. This is based on a monolingual ideology with its roots in 16th century Europe, reaching its breakthrough during the late 18th century revolutions and Enlightenment (Lüdi, 2015, p. 214). According to this ideology, communicative problems are to be mitigated through the use of one single language, whereas linguistic diversity is problematic and undesirable.

There are several reasons why this attempt at a solution is deceptive. Language acquisition is not merely a matter of a teaching and learning effort, but it is affected by ideologies, social identities, power and agency. In a socially and economically unjust urban environment, policing a diverse population to communicate using the same second language becomes, at best, a privilege reserved for the most prosperous communities. As Peter De Costa and Bonny Norton (2017, p. 8) conclude:" Language learning is situated and attentionally and socially gated". In addition, multilingual individuals experience obvious benefits that are particularly valuable to knowledge production, such as enhanced cognitive functions and a higher likeliness of gaining new and creative insights (Yanaprasart \& Lüdi, 2017).

Linguistic inequalities and its effects concern questions of recognition, identity, and, ultimately, morality. In the scientific tradition emanating from German philosopher George Wilhelm Friedrich Hegel (1977 [1807], pp. 113-114), recognition is either mutual - and therefore equal - or non-mutual and therefore unequal. An individual's lack of recognition with regard to their identity is considered a form of oppression or negation of the self's expected rights (Honneth, 1992, p. 190). Due to a historical paradigm shift of class or estate partly losing its significance in favour of other foundations for social identity, such as ethnicity, gender and 
sexuality, language is today considered more intimately connected to recognition than before (Taylor, 1994, pp. 31-32; 53-55). Not being equally recognized as a speaker means not being fully recognized as a conscious being.

A significant share of studies on linguistic diversity has been conducted in the educational sphere. Some findings state that in multilingual regions, such as Barcelona and Switzerland, enabling the use of multiple languages in education is not only possible but also adds value to students. Universities in both regions use innovative ways of teaching, team work and interaction - such as communicative applications and instant translation tools - required to make multilingualism productive and feasible in an organisational environment (Yanaprasart \& Lüdi, 2017). In the case of the private and public transnational trade sector, Amy Artelt and Judith Sawaf (2013) observe a vast range of auxiliary devices supporting various European partners in successfully conducting multilingual operations.

One of the tools aiding multilingual dialogue is interpretation. The challenges of interpretation are well documented. First, naturally, the extra time spent on interpretation is roughly double that of a 'normal' dialogue. Second, data loss, for example, when data showing essential sociological variables - such as dialects and sociolects - are being translated into a standard version of the language being interpreted. Third, using a non-professional interpreter from the local area or a particular ethnic group during field work can often result in the researcher staying unsure of whether they have thoroughly understood the purpose of their research or if there has been a misunderstanding. Fourth, the nuances of irony, humour, rhetoric and politically ambiguous concepts all run a severe risk of being lost in translation (Bujra, 2011, pp. 5-6). Finally, the perception of time could be a challenge. Indo-European languages have past, present and future tenses (with some variations), whereas many other language groups do not. This aspect can be easily lost in translation. Another side of the coin is 'economic time' vs 'social time', often creating misunderstandings in the development of co-operations (Mikkelsen, 2005, p. 329).

\subsection{Culture}

Culture, in terms of working and personal culture, for example traditions, procedures and perspectives, has large implications for the interrelations and interactions between the collective and the individual. An individual's behaviour is often dramatically affected by the working group and workplace they are a part of or interacting with due to institutionalized cultural practices associated with that place and group. However, individuals themselves are also capable of affecting workplace culture to a certain extent, since they carry with them personal attributes, of which some are in turn affected by outside norms and identities such as gender (Somerville, 2005).

There is no one answer to questions of whether increased diversity between individuals is beneficial or restraining to working cultures. Indeed, there exist certain benefits of linguistic and/or ethnic homogeneity in work teams such as reduced misunderstandings and increased consensus and efficiency, whereas mixed teams can contribute to stress and anxiety. Simultaneously, known positive outcomes of mixed teams include reduced prejudice (Offermann, Matos, \& Basu DeGraaf, 2014). In any case, many parts of today's workforce are becoming increasingly diverse by design or by default, partly as a necessity and partly as a deliberate attempt at tackling challenges of discrimination. In the end, the main issue is therefore not to define whether diversity is beneficial, but rather how to optimize management of an urban environment of unavoidable linguistic diversity and its consequent communication challenges (Yanaprasart \& Lïdi, 2017).

As experience from an international project between researchers and practitioners from Ghana and the UK shows, there is a need for reassessment in addressing multiple or conflicting world views even within the same epistemic community in order to help support intended beneficiaries of such projects to meet their needs and fulfil aspirations (Simon et al., 2003). Patchareerat Yanaprasart and Georges Lüdi (2017) conclude that, in the case of academia, little is yet known about how to manage diversity challenges in general, as the objectives in diversity policies are mainly set at a strategic level, such as to favour gender mainstreaming. Managing linguistic diversity is not expected to be an exception from the rule and could therefore be considered a blind spot for academic institutions.

\subsection{Framework for analysing complexity of co-production settings in relation to epistemic communities, linguistic diversity and culture}

Based on the literature review, we suggest the following framework. It combines the concepts of epistemic standpoint that participants have (see more in Section 3.1), language(s) they speak to a varying degree (see Section 3.2) and culture they more or less share (see Section 3.3). Each of these concepts has three categories that we differentiate - individual, group and working. When analysing a specific facilitated group, one would look at all the concepts simultaneously with their respective categories.

Since, for example, the concept of culture would be difficult to assess numerically, one would look at the level of diversity (i.e. its range) within each category in the facilitated group. The level of diversity would be subjectively assessed by the user of the framework (facilitators and/or process leaders as we recommend). It could have only high and low diversities or high, medium and low, or more, for example. To avoid numerical representation, we recommend to use the shades of one colour to illustrate the level of diversity - where the diversity increases with darker shades. Fig. 1 illustrates the template that one can fill out based on the facilitated group of assessment.

Adrian Snodgrass and Richard Coyne (1997) discussion on the hermeneutic aspects of designing, we acknowledge workshop design, facilitation and process management to be pervaded by subjective presuppositions influencing all design processes; namely, the pre-conceived understandings of the process leader regarding the studied object (in our case, the participants) will inform the process design (Snodgrass \& Coyne 1997, pp. 13-14; 26), then follow a learning process guided by a series of enquiring dialogues between the process leader (or facilitator) and these objects, ultimately transforming the former's understanding of the latter beyond 


\begin{tabular}{|l|l|l|l|}
\hline $\begin{array}{r}\text { Concept } \\
\text { Category }\end{array}$ & $\begin{array}{c}\text { Epistemic } \\
\text { standpoint }\end{array}$ & $\begin{array}{c}\text { Linguistic } \\
\text { diversity }\end{array}$ & Culture \\
\hline Individual & & & \\
\hline Working & & & \\
\hline Group & & & \\
\hline
\end{tabular}

Fig. 1. Matrix for complexity assessment of transdisciplinary co-production settings in relation to epistemic communities, linguistic diversity and culture with respective categories: individual, working and group.

that of initial subjectivity (Snodgrass \& Coyne 1997, pp. 21-22). Therefore, according to the proposed framework, interpretation and assessment of a workshop will initially be understood by the process leader based on their previous knowledge of the participants and from previous experiences of workshops, epistemic communities, linguistic diversity, and cultural diversity. Gradually, however, this understanding will transform as the framework is used in the planning of several workshops, thereby providing more answers to the questions that the framework poses onto the various constellations of participants.

Epistemic standpoint is here characterised in relation to the categories individual, working and group. The individual epistemic standpoint is the school of thought to which each individual in the facilitated group belongs. The level of diversity will define how many different individual epistemic standpoints are present in the group - the more individual standpoints, the higher the level of diversity would be. The working epistemic standpoint is closely related to the occupation that the participant of the workshop has and the diversity of epistemic standpoints in their daily work situation. The more diverse working standpoints are present in the facilitated group, the higher the level of diversity. The epistemic standpoint of the facilitated group as a whole is closely related to the potential shared standpoint participants have within the facilitated group or depending on the design and length of the facilitation process - the shared standpoint they obtain in the process. The diversity would be high when participants come from very distant epistemic communities and there are low chances of building a shared standpoint.

Similarly, linguistic diversity is differentiated between the individual, the working and the group. The linguistic diversity of the individual category is related to the number of mother tongues that are spoken by the individual participants of the workshop. The diversity is high when there are many mother tongues present in the facilitated group. If a lingua franca is spoken at the workplaces of the facilitated group members (everybody is sharing the same working language), then the linguistic diversity of the working category is low. If there are several languages used as working languages - the diversity is high (the more languages spoken at work, the higher the diversity). The linguistic diversity of the group category relates to the mono- or multilingualism of participants: they might speak several languages to some extent, however, not to be proficient enough to use them as working languages. The more of such languages that are present in the facilitated group, the higher the linguistic diversity for the group category.

Finally, we differentiate three categories of culture - individual, working and group. Individual culture is what each participant of the facilitated group brings into the room with them, such as norms, customs, personal identity, etc. High diversity in this regard would be if the group represents many different types of backgrounds. Working culture can be defined by norms and customs at the workplaces the participants of the facilitated process belong to and bring with them to the event of analysis. High diversity in this regard would be when a facilitator and/or process leader can identify man such working cultures and subcultures. Group culture is the one that (has a possibility to) emerge in the facilitation process and thereby apply to the facilitated group as a whole. High diversity in this regard is when participants can bring in and to a lesser extent adjust their individual and working cultures.

One can use this framework to see the average level of complexity related to epistemic communities, linguistic diversity and culture (the average shade of the matrix). This could be done both at the preparatory stages of the event and as evaluation at the end of the transdisciplinary facilitation process. However, identifying the levels of diversity in each category of each concept would help raise awareness about the complexity of the context in which they are working in relation to epistemic communities, linguistic diversity and culture in more detail. Assuming that the facilitator has previous experience or at least knows where to look for facilitation tools and methods, the increased awareness should help to make a better selection. In case of high linguistic diversity, for example, one might want to consider to have additional facilitator(s) who speak the local language(s) (for examples, see Section 4.1) and/or have an interpreter. Further studies are necessary to map specific tools and methods to exemplify how the levels of diversity in the selected concepts of the proposed framework would affect the selection of tools and methods.

\section{Empirical application and findings from the three selected locations}

\subsection{Context of empirical studies and testing of the proposed framework}

The context of the empirical study is three workshops (WS) within the INTERCONNECT project ${ }^{2}$ an ongoing international project (2017-2020) that received a flagship status on the European level. The project aims to reduce car dependency in the South Baltic area by providing user-oriented sustainable public transport in and between the participating regions and in cross-border commuting. There are nine main partners and 11 associated partners from the Blekinge region (Sweden), the Guldborgsund municipality

\footnotetext{
${ }^{2}$ See http://interconnect.one/
} 
(Denmark), the Rostock municipality (Germany), the Tricity metropolitan area (Gdansk, Gdynia, Sopot, Poland), the Klaipeda municipality (Lithuania), and the Viimsi municipality (Estonia). Within the project, three main areas are in focus - demand, supply and governance of public transport. One of the project working packages called "Evidence, knowledge and experience" aims to assist local stakeholders of the partner areas in identifying current and future needs of the passengers, to facilitate co-production of a vision for sustainable public transport in the region, to identify a selection of sustainable solutions in order to address current and future challenge and to create a pathway to achieve it.

Through a co-production process between Blekinge Institute of Technology (the hosting institution that provided the project with the team of facilitators) and Region Blekinge (the project manager) ${ }^{3}$ the format to support a working package with stakeholder workshops in focus was defined and agreed upon. It was based on a community planning process model (Robèrt, Borén, Ny, \& Broman, 2017) which aims to define an approach to sustainable transport planning. Development of this model was guided by the Framework for Strategic Sustainable Development (Broman \& Robèrt, 2017) with its backcasting from principles approach (Holmberg \& Robèrt, 2000). The model is based on four interdependent planning perspectives: resource bases, surfaces, technology and governance.

To get a better understanding of the local context of three selected partner locations, Karlskrona (Sweden), the Tricity metropolitan area (Gdansk, Gdynia, Sopot, Poland), and Klaipeda (Lithuania), local partners of the project were invited to a dialogue that was ongoing for several months before the workshops. Local stakeholders as well as international partners got an invitation to attend the event. The main language of the workshops was English, while in each location different interpretation services were implemented.

As mentioned by Barbara Kawulich (2005), an observer can be excluded from the process due to the language of certain epistemic communities to which the observer is unfamiliar. In all three workshops, an additional layer to the risk of exclusion was the lack of a common spoken language that all participants were fluent in. A facilitator understanding both Swedish and Polish was at hand in two of the three workshops that occurred in Sweden and Poland, respectively. This enabled not only observation of the process and participants' behaviour, but also understanding of the content of the discussion. In the last workshop, taking place in Lithuania, however, interpretation of the content was achieved only through oral presentation of summaries during the day and written forms with the notes from the discussions that were translated into English. However, nuances related to language as metalanguage (expressing underlying meanings) (Agar, 1996) could have been 'lost in translation' in all workshops.

We tested the proposed framework in each location post factum, in order to evaluate the outcomes of the workshop designs done through a transdisciplinary co-production process. However, if the framework had been used in the preparatory stages of the workshop, it could have been used as supportive materials for development of workshops.

In the first workshop (WS1) in Karlskrona, in February 2018, there were 43 participants originating from different countries, speaking different mother tongues and representing diverse epistemic communities. Most of the participants were local stakeholders living and working in the Blekinge region, with the exception of those project partners living and working in Germany and Poland. There were representatives from academia, public and private sectors, all working with questions of transport from different angles. English was spoken as a lingua franca in the large group discussions and presentations. However, when it came to break-out sessions in small groups, Swedes preferred to speak Swedish if the group was linguistically homogeneous. This meant that multilingual table leaders were collecting information delivered orally in Swedish and documenting it on flipcharts (for later presentation) and other reporting forms in English. The experience seemed not to have affected the group dynamics much, although, as one of the table leaders said: "In the mixed group participants were a bit more hesitant to express themselves [than in the native language groups]" (Wälitalo, 2018). Despite the diversity of thought collectives, participants came to the same or very similar conclusions in regard to the future of transport in the region. Many of these participants had worked together in the past, which might help to explain their resembling ways of thinking.

When applying the framework, the facilitated group can be evaluated in the following way. WS1 (see Fig. 2) had participants representing several working epistemic standpoints. This we could assess from the participants' list and information regarding their current occupation. As for individual epistemic standpoints, it could be challenging to make a detailed assessment without accessing further information about the participants. However, based on the diversity of the working epistemic standpoints, one can estimate that individual epistemic standpoints would also be of a bit higher diversity. As for group epistemic standpoint, this can also be seen as similar diversity to individual and working, however, perhaps, a bit higher diversity than working and lower diversity than individual, as most of the participants were working with questions of transport.

Participants of WS1 spoke several languages, both mother tongues and secondary languages, including the lingua franca. Individual linguistic diversity could be assessed as lower than individual epistemic standpoint, as more than a half of the participants had Swedish as their mother tongue. However, group linguistic diversity could be assessed as quite high, as most of the participants spoke at least two languages. The working languages could be assessed as similar to individual, as most of the participants spoke lingua franca.

Individual culture was quite diverse, as participants came from different cultures. However, with the exception of the partners from Germany and Poland, the rest were accustomed to Swedish working culture, so it can be seen as relatively low diversity with regard to working culture. The cultural diversity of the facilitated group as a whole had an increase throughout the day as the workshop was designed to particularly highlight Swedish traditions of, for example, fika (coffee break) and celebration of semla day (the day of special pastry called semla, a cream-filled bun). By celebrating this diversity and welcoming all the different thoughts and

\footnotetext{
${ }^{3}$ For more details, see Thematic Report for the project (Borén \& Ny, 2018).
} 


\begin{tabular}{|l|l|l|l|}
\hline Concept & $\begin{array}{c}\text { Epistemic } \\
\text { standpoint }\end{array}$ & $\begin{array}{c}\text { Linguistic } \\
\text { diversity }\end{array}$ & Culture \\
\hline Individual & & & \\
\hline Working & & & \\
\hline Group & & & \\
\hline
\end{tabular}

Fig. 2. Complexity assessment of transdisciplinary co-production settings of WS1 in relation to epistemic communities, linguistic diversity and culture.

\begin{tabular}{|l|l|l|l|}
\hline \multicolumn{1}{|c|}{ Concept } & $\begin{array}{c}\text { Epistemic } \\
\text { standpoint }\end{array}$ & $\begin{array}{c}\text { Linguistic } \\
\text { diversity }\end{array}$ & Culture \\
\hline Individual & & & \\
\hline Working & & & \\
\hline Group & & & \\
\hline
\end{tabular}

Fig. 3. Complexity assessment of transdisciplinary co-production settings of WS2 in relation to epistemic communities, linguistic diversity and culture.

opinions, however, the workshop design was meant to reunite everyone in a traditional way and help them to get to know each other better rather than dividing them.

In the second workshop (WS2) in Gdynia, in February 2018, there were 53 participants coming mainly from Poland, in particular from Pomerania, Warmia and Mazury, represented by stakeholders from the local government, municipalities, service providers, academia and other relevant institutions. Most of them spoke Polish and only some of them understood or spoke English. Moreover, there was one participant who spoke English and French, but not Polish. It was the first time that many of the participants met and worked together. For the duration of the workshop, an interpreter was hired who performed simultaneous (whisper) translation in smaller groups and consecutive interpretation for the entire audience. Simultaneous interpretation saved a lot of time; however, it was often a summary of what had been said. Consecutive interpretation doubled the time of the sessions, at the same time delivering interpretation paragraph after paragraph, which created the additional challenge of keeping the attention of the audience.

From the working culture perspective, workshops are not commonly used in Poland to facilitate multi-stakeholder dialogue. In order to attract participants, local organisers decided to change the title of the event from 'workshop' to 'seminar', which could be seen as misleading. During the event itself, participants were visibly uncomfortable with the format: they were unwilling to express their opinions during the sessions or ask questions at the presentations; when the question for discussion was not perceived as important for them, the session went very quickly, as not many people wanted to participate actively. Some of them left at different stages throughout the day. However, the questions of direct relevance that were identified as 'burning issues' (challenges they are facing right now at work) created very lively discussions, expressing different, sometimes contrasting opinions (Kuik, 2018; Wolniarska-Roszak, 2018).

Using the proposed framework for average complexity assessment, one can see that WS2 was characterised by a high diversity of epistemic standpoints, languages and culture (Fig. 3). It was pervaded by linguistic diversity (with no common individual, working and group languages), multicultural (representing different cultures and working in different contexts - high diversity, with a limited possibility to develop a common group culture) and involved different epistemic standpoints as participants represented a wide range of stakeholders with different cultural and working backgrounds with a limited possibility to develop a common epistemic standpoint throughout the day. Such a context was very demanding from the organisers' side as they also came with their own cultures, epistemic standpoints and linguistic diversity. The size of the group created additional pressure of keeping the attention and motivation throughout the day.

In the third workshop (WS3) in Klaipeda, in March 2018, there were 17 participants representing the Klaipeda region. They were all either working for the municipality or for the city authorities. Most of them spoke Lithuanian and some spoke and/or understood English. As a solution to the multilingual challenge here, simultaneous translation through headphones was provided. Although it seemed like an optimal solution for saving time and providing sufficient interpretation, some words got lost in translation, for example, 'accessibility' ${ }^{4}$ in Lithuanian was translated as 'prieinamumas' and back into English as 'reachability' ${ }^{5}$. These two terms can

\footnotetext{
4 "Accessibility is the ability of people to reach goods or services as measured by their availability in terms of physical space, affordability and appropriateness. But accessibility also refers to the provision of services and facilities, job opportunities, education and housing, as well as the means of reaching them" (Simon, 2016; Waters, 2016).

${ }^{5}$ According to Oxford Dictionary, reachable means "able to be reached; accessible or achievable", as well as "able to be contacted", purely in terms of being able to reach something: "a lush tropical island only reachable by seaplane" or "make sure that you set goals that are reachable" ('reachable | Definition of reachable in English by Oxford Dictionaries', n.d.).
} 


\begin{tabular}{|l|l|l|l|}
\hline Category & $\begin{array}{c}\text { Epistemic } \\
\text { standpoint }\end{array}$ & $\begin{array}{c}\text { Linguistic } \\
\text { diversity }\end{array}$ & Culture \\
\hline Individual & & & \\
\hline Working & & & \\
\hline Group & & & \\
\hline
\end{tabular}

Fig. 4. Complexity assessment of transdisciplinary co-production settings of WS3 in relation to epistemic communities, linguistic diversity and culture.

have different definitions and underlying assumptions and can therefore not be assumed to be used interchangeably. Moreover, in the process of simultaneous translation it was difficult to monitor whether the intonations were kept to underline certain statements. As culture and background of the participants were if not the same, but very similar, the discussions were calm, and conclusions corresponded to one another (Valadka, 2018).

The WS3 (see Fig. 4) was quite homogenous among participants (low diversity in relation to epistemic standpoints, linguistic diversity and culture), but the organisers came from very different contexts, which created a challenge in facilitating the day as the language barrier (no common working language between participants and organisers) was the strongest obstacle. One cultural element that united them all was the International Women's Day that was widely celebrated in the past, but only seldom nowadays. It was used as a starting point for the day to share a cultural tradition with all participants and provide a platform for strengthening the group culture.

These three observations illustrate how epistemological, cultural and linguistic diversities intersect and interact in the shaping of a transdisciplinary multilingual urban planning dialogue. When applying this framework to the three selected cases, we had the comparative aspect in mind (the shades of grey can be compared between the cases). However, what it doesn't show is the relation between, for example, the number of working languages spoken in the room and the number of participants speaking all those individual languages. For example, out of 53 participants in Poland, all except one spoke Polish. On average, they did not have a common working language. However, there were not so many different working languages in total. The diversity of epistemic standpoints was especially evident during the first and second workshops, when conversations were ongoing at the breaks, but these had quite different outcomes nonetheless. The co-production process at these workshops provided a good platform for knowledge cocreation, as diversity of epistemic communities in small discussion groups was encouraged (both on voluntary basis - participants were invited to create discussion groups with people they have never worked with before; and through planned distribution of participants based on their affiliation). The third workshop, however, does seem to indicate that linguistic and cultural diversities do not categorically endanger transdisciplinary group work when intentionally managed. However, the presence of 'calm' discussion and absence of differing conclusions and critique may equally so be viewed as a lack of co-production of knowledge, in which a certain degree of critique and conflicts can be beneficial (Brouwer et al., 2016; Perry \& Atherton, 2017).

Discussions in all three workshops were facilitated by a common understanding of the issue, but this was dependent on efficient communication between participants. When language barriers emerged, common understanding decreased somewhat. The first workshop, on the other hand, maintained a lingua franca ideal of English while Swedish was being used as an informal majority language, apparently leading to some participants being less active. In that way the questions of recognition, identity and morality were addressed by the organisers for the formal part of the event. However, in the breaks the participants were left without an interpreter, which means that networking and socialising were affected by it and the group naturally fell apart into smaller groups of those speaking one common language or lingua franca (mainly, English, Swedish and Polish).

Furthermore, throughout all three workshops, cultural norms - such as the presence versus absence of workshops as part of the professional routine - contributed to challenging the degree to which discussion matters were treated. The professional cultural background was one of relative familiarity during the first and third workshops, whereas participants in the second workshop experienced a clash of both epistemic and cultural collective values while simultaneously facing the challenge of linguistic diversity. Participants of the third workshop had more in common epistemically, linguistically and culturally than those of the second.

\subsection{Additional findings from the framework application}

The starting point of this article was to investigate whether providing proper means for equal possibility of using one's language in linguistically diverse dialogue should be considered essential although insufficient in the context of multicultural transdisciplinary urban planning groups. Furthermore, each particular context needs to be addressed beforehand on its own terms with regards to its diversity challenges. The three observed geographical locations experienced only minor differences regarding official content and purpose but were significantly affected by nuances in culture and linguistic diversity, on top of the aforementioned general challenges of epistemic diversity. All things considered, the workshops displayed a relative awareness and preparedness regarding linguistic diversity challenges, but were less concerned with the sum of linguistic, epistemic and cultural clashes. As we see through the lens of the framework, multicultural, multilingual transdisciplinary groups require thorough preparation for co-production facilitation in order to address the topic of discussion and acknowledge diversity yet in a just way. It was found that the following elements should be taken into consideration to promote effective co-production: 


\subsubsection{Disciplinary integrity}

The prerequisites for each participating discipline or profession need to be taken into account. Some may have less access to intellectual content than others, and others may have limited experience of practical problem-solving. Regardless, maintaining an equal ground for each discipline and profession to partake in group work, discussion and knowledge production is essential. This challenge may risk being overlooked in situations also facing linguistic diversity.

\subsubsection{Linguistic equality between participants}

Participating actors, stakeholder groups and individuals need to be able to speak a language of their choosing, rather than a predetermined lingua franca. One language must not be favoured above others and participants must still be prepared to work together rather than in enclosed linguistic communities. This principle needs to be routinely reinforced and acknowledged, in order to secure the active participation of all stakeholders in mitigating a complex issue. Different types of interpretation can be at hand in this process, especially when moving towards a higher complexity, however the organisers need to weigh all the pros and cons of different forms of interpretation and be ready to compensate for risks.

\subsubsection{A working culture of mutual respect}

Whereas participants hail from diverse normative conditions and traditions of working, that is working culture, it is essential that an additional culture of mutual respect needs to be fostered in a multicultural, multilingual and transdisciplinary group. This requires both understanding and a certain level of attention paid to the background of various participants. Naturally, however, facilitators of workshops, meetings and other urban planning contexts have limited access to information regarding the background of the participants.

\subsubsection{Simultaneous mitigation and informed facilitation}

The main challenge is to combine and tackle the aspects of epistemic communities, linguistic diversity and culture during the same event or situation. This challenge needs to be mitigated by introducing awareness-raising models, as described in Section 3.4. If facilitators are made aware of the complexity partly related to group diversities when preparing for the event, the likeliness of them being able to manage such diversities is significantly increased.

\section{Evaluation of the framework}

\subsection{Critical assessment}

There are several aspects of co-production that we can assess the framework upon (Polk, 2015), such as inclusiveness, crosssectoral understanding and applicability to different contexts. Additionally, we assess the framework from the time perspective.

The proposed framework accounts for potential differences in a transdisciplinary group to prepare process leaders (or facilitators) to conduct more inclusive workshops or meetings. Enabling every participant to express themselves and understand others fully empowers an individual to contribute to the process and confirms their recognition.

One could argue that there are other aspects that could be included in the framework. We are not suggesting that the framework is comprehensive. Adding more aspects would not necessarily increase its usefulness, though. On the contrary, it might become counterproductively complex. Alternatively, we suggest that there could be supporting tools and methods that could go along with the framework to, for example, quantify the assessment of the situation that process leaders are concerned with and recommend concrete steps to change their process.

One of the underlying purposes of co-production is to increase the understanding between different sectors in a transdisciplinary context. Addressing complexity of transdisciplinary groups could lead to more inclusive processes and provide a platform for a more open and efficient sharing of knowledge and experiences. Of course, using this framework does not ultimately mean that a better understanding between the sectors will immediately occur. However, not addressing aspects discussed in the above framework might hinder mutual understanding substantially.

Finally, the aspect of time can be evaluated differently using this framework. On the one hand, time is money, and in a Western planning model (Mikkelsen, 2005) 'economic time' plays an important role in the planning of processes. We intend to do more within a shorter period of time: in other words, to be more efficient. In this case, an increase in complexity would require more time for preparation of the workshop or event and the workshop or event itself would last longer, for example, due to the chosen type of interpretation (see Section 3.2). On the other hand, time can be seen as an asset in the process - the more time is put into dialogues (considering there is a well-prepared process and content), the greater are the chances for understanding the situation and each other's perspectives and for avoiding segregation in the group. It is suggested by Britha Mikkelsen (2005) that in a Western tradition 'social time' has lost its value while this is not true for indigenous peoples, for example.

Since it is based on the literature and empirical studies, we anticipate that the framework developed here will be useful in assisting preparation for the facilitation and evaluation of many different kinds of dialogues, not only in transdisciplinary contexts of complex problem-solving. It could also be a potentially useful assessment framework for participatory processes in a wide range of contexts such as kindergartens, schools, governance and businesses in which diversities pose communicative challenges. The framework could perhaps also be used as a basis for the development of new and innovative communication tools, applications and strategies for facilitating groups encountering these diversities. We further believe that such a framework could be used as a 
complementary tool to a certain community planning process model (Robèrt et al., 2017), as a starting point for the planning of transdisciplinary co-production work on local, national and international levels.

\subsection{Comparison with other studies}

In our literature studies we have not been able to find a framework for the assessment of complexity in multilingual multicultural multi-stakeholder transdisciplinary environments. However, we found several publications to be interesting to refer to here and we analyse them in more detail below (Armitage, Berkes, Dale, Kocho-Schellenberg, \& Patton, 2011; Barreteau, Bots, \& Daniell, 2010; Dafouz \& Smit, 2016; König, Diehl, Tscherning, \& Helming, 2013; Schuttenberg \& Guth, 2015; Wuelser et al., 2012).

The identified publication that was the closest in relation to the context of this paper was written by Derek Armitage and colleagues (Armitage et al., 2011). There, they describe the challenges they have been facing during the co-production process - the role of power, the varying degree of shared understanding and the normative context. The role of power in their work was defined as the "willingness to recognise and accept existence of different systems of understanding and practices" (Armitage et al., 2011, p. 997). Compared to the aspects of our framework, it is somewhat similar to the combination of disciplinary integrity and a working culture of mutual respect (see Section 2). In relation to that, Derek Armitage and his colleagues write about shared understanding in terms of acceptance of different schools of thought. We, on the other hand, view normative context - shared desire to use knowledge - as an embedded value of co-production and as more related to the content of the workhop or event rather than to the work with participants in its own.

Another study that our framework could be compared to is dealing with multilingualism in education. Emma Dafouz and Ute Smit suggest the ROAD-MAPPING framework with six relevant components (Dafouz \& Smit, 2016, pp. 403-409): "Roles of English, Academic Disciplines, (language) Management, Agents, Practices and Processes and Internationalisation and Glocalisation ${ }^{6}$ ". The authors address academic disciplines (closely related to epistemic communities in co-production processes) and language management (using similar concepts as we do) similarly to our approach, analysing the participants' side of the process. Furthermore, they look at factors - agents, practices and contexts - that we view as external and that could be monitored but do not affect the complexity of transdisciplinary environments.

A framework for structuring interdisciplinary research management (König et al., 2013) has a broader focus on all the roles and processes related to the management of research than we have in the proposed framework. In relation to the framework by Bettina König and colleagues (2013), we focus on the interdisciplinary culture quadrant, focusing on the facilitator (or process leader as we suggest here) and what aspects of complexity should be taken into account when preparing for a transdisciplinary process. We see our framework as complementing the one proposed by Bettina König and colleagues (2013).

Two of the frameworks focus on knowledge co-production (Schuttenberg \& Guth, 2015; Wuelser et al., 2012), while the framework developed by Gabriela Wuelser and colleagues (2012) is also considering the notion of sustainable development and the policy process. These frameworks are in line with ours as some of the aspects discuss overlap, for example, elements of sustainability objectives (Wuelser et al., 2012), which correspond to some of our additional findings, and facilitated collaboration (Schuttenberg \& Guth, 2015) as a platform for knowledge co-production that we develop further in our framework.

Finally, the framework that created additional afterthought reflecting back on the workshops analysed in this paper was devoted to communication about participation to and with the participants (Barreteau et al., 2010). The authors claim that transparency about participation being "upfront and precise" should prevent participants from rejecting the participation in the event. Based on the long discussion with the local organisers of the workshop in Poland about their working culture, customs and practice, the decision was made to replace the word 'workshop' with 'seminar' (see Section 4.1). The local organizers doubted the willingness of participants to join a workshop format as it is not common in the local culture and practices. On the one hand, this might have resulted in inactive participation in the process during the day; on the other hand, for the local organizers it was important to have all those participants present in the room in order to initiate further dialogue. In the case of this workshop, being precise was not enough to ensure the expected outcomes. Perhaps it is a cultural change that needs to happen to accept a workshop format there? To answer this question, further research would be necessary.

What is interesting to note is that studies performed by six different groups of scholars, whose research is described in this section, and us, are attempting to increase inclusiveness in co-production processes. This underlines the importance of the work that we present in this article.

\section{Concluding remarks and further work}

In line with its purpose, this article has presented a framework for analysing complexity within urban planning by integrating three significant factors of contemporary diversity challenges: varying epistemology, linguistic diversity and multiculturalism. These three factors play major roles when present in dialogue and need to be approached to create the best conditions for moving forward with the issues that such dialogues are supposed to manage. The framework is aimed at the process leaders, mostly facilitators of workshops or co-production processes. It was found that, while being skilled in mitigating conflicting interests and ideas between participants, facilitators need further developed techniques for dealing with wider multiple challenges of diversity within groups.

\footnotetext{
${ }^{6}$ Glocalisation - "the practice of conducting business according to both local and global considerations" ('glocalization | Definition of glocalization in English by Oxford Dictionaries', n.d.; Robertson, 2014).
} 
Future studies on the subject also have the potential of further developing the here suggested framework by identifying levels of complexity and mapping specific tools to address complexity at each level, as well as by integrating other factors of complexity, such as political and institutional contexts, as well as diversity of gender and age in the facilitated group.

\section{Funding}

This work was supported by the Researchers at Risk programme from MISTRA, the Swedish Foundation for Strategic Environmental Research; Blekinge Institute of Technology, Chalmers University of Technology and Mistra Urban Futures.

\section{CRediT authorship contribution statement}

Varvara Nikulina: Conceptualization, Methodology, Validation, Investigation, Writing - original draft, Writing - review \& editing, Visualization. Johan Lindal: Conceptualization, Methodology, Validation, Writing - original draft, Writing - review \& editing. Henrikke Baumann: Conceptualization, Writing - review \& editing, Supervision. David Simon: Conceptualization, Writing review \& editing, Supervision. Henrik Ny: Conceptualization, Writing - review \& editing, Supervision.

\section{Declaration of Competing Interest}

None

\section{Acknowledgements}

We thank the INTERCONNECT project for giving an opportunity to discover and address the challenge, as well as to performing the empirical study. We are grateful to Mistra Urban Futures' Research School for supporting the development of the idea. We are thankful to interviewees for empirical data, and reviewers and colleagues at Blekinge Institute of Technology for constructive feedback, as well as Oliver Örnmyr for systemic critical assessment of the work. We are also thanking the reviewers for further literature recommendations and valuable feedback that helped improve the original manuscript.

\section{Appendix A}

Table A1

List of interviewees.

\begin{tabular}{lll}
\hline Name & Date & Location of the WS \\
\hline Lisa Wälitalo & March 18, 2018 & Karlskrona, Sweden \\
Anna Wolniarska-Roszak & March 26, 2018 & Gdynia, Poland \\
Rokas Valadka & May 28, 2018 & Tlaipeda, Lithuania leader \\
Jarosław Kuik & May 31, 2018 & Gdynia, Poland \\
\hline
\end{tabular}

\section{References}

Agar, M. (1996). The professional stranger: An informal introduction to ethnography (2nd ed.). San Diego: Academic Press.

Armitage, D., Berkes, F., Dale, A., Kocho-Schellenberg, E., \& Patton, E. (2011). Co-management and the co-production of knowledge: Learning to adapt in Canada's Arctic. Global Environmental Change Part A, 21(3), 995-1004. https://doi.org/10.1016/j.gloenvcha.2011.04.006.

Artelt, D., \& Sawaf, H. (2013). Speech-enabled unified communications: Overcoming the multilingual challenges of the European Market. In A. Neustein, \& J. A. Markowitz (Eds.). Where humans meet machines (pp. 59-77). . https://doi.org/10.1007/978-1-4614-6934-6_4.

Barreteau, O., Bots, P. W. G., \& Daniell, K. A. (2010). A framework for clarifying "Participation" in participatory research to prevent its rejection for the wrong reasons. Ecology and Society, 15(2), https://doi.org/10.5751/ES-03186-150201.

Baumann, H. (2009). Don’t fence me in. In Boons Frank, \& Jennifer Howard-Grenville (Eds.). The social embeddedness of industrial ecology Edward Elgar.

Benveniste, E. (1971). Problems in general linguistics. Coral Gables, Fla: University of Miami Press.

Borén, S., \& Ny, H. (2018). Summary from activity 3.2: Workshops on sustainable paths for public transportKarlskrona: Blekinge Institute of Technology33 (No. Thematic report (WP 3.2).

Broman, G. I., \& Robèrt, K.-H. (2017). A framework for strategic sustainable development. Journal of Cleaner Production, 140, 17-31. https://doi.org/10.1016/j. jclepro.2015.10.121.

Brouwer, H., Woodhill, J., Hemmati, M., Verhoosel, K., \& van Vugt, S. (2016). The MSP guide: How to design and facilitate multi-stakeholder partnerships. https://doi.org/ $10.3362 / 9781780446691$.

Brown, V. A. (2008). A collective social learning pattern. EuroPLoP, 2008, 1-14.

Bujra, J. (2011). Lost in translation? The use of interpreters in fieldwork. In V. Desai, \& R. B. Potter (Eds.). Doing development research (pp. 172-179). London: SAGE Publications, Ltd.

Creswell, J. W., \& Poth, C. N. (2018). Qualitative inquiry and research design: Choosing among five approaches (4th ed.). Los Angeles London New Dehli Singapore Washington DC Melbourne: SAGE international student edition.

Dafouz, E., \& Smit, U. (2016). Towards a dynamic conceptual framework for english-medium education in multilingual university settings. Applied Linguistics, 37(3), 397-415. https://doi.org/10.1093/applin/amu034.

De Costa, P. I., \& Norton, B. (2017). Introduction: Identity, transdisciplinarity, and the good language teacher: Introduction: Identity, transdisciplinarity, and the good language teacher. Modern Language Journal, 101(S1), 3-14. https://doi.org/10.1111/modl.12368. 
Esson, J., Gough, K. V., Simon, D., Amankwaa, E. F., Ninot, O., \& Yankson, P. W. K. (2016). Livelihoods in motion: Linking transport, mobility and income-generating activities. Journal of Transport Geography, 54, 34-40. https://doi.org/10.1016/j.jtrangeo.2016.04.008.

Fleck, L., Trenn, T. J., Merton, R. K., \& Bradley, F. (1979). Genesis and development of a scientific fact (Repr. 11. Aufl)Chicago [u.a]: Univ. of Chicago Press.

Flowerdew, R., \& Martin, D. (Eds.). (2005). Methods in human geography: A guide for students doing A research project(2nd ed.). Harlow, England; New York: Prentice Hall.

Glocalization | Definition of glocalization in English by Oxford Dictionaries. (n.d.). Retrieved 22 October 2018, from Oxford Dictionaries | English website: https://en. oxforddictionaries.com/definition/glocalization.

Haas, P. M. (1992). Introduction: Epistemic communities and international policy coordination. International Organization, 46(1), 1-35.

Hegel, G. F. W. (1977). Lordship and bondage. The phenomenology of spirit. Oxford: Oxford University Press111-119 (translated by A.W. Miller).

Holmberg, J., \& Robèrt, K.-H. (2000). Backcasting from non-overlapping sustainability principles-a framework for strategic planning. The International Journal of Sustainable Development and World Ecology, 7(4), 291-308.

Honneth, A. (1992). Integrity and disrespect: Principles of a conception of morality based on the theory of recognition. Political Theory, 20(2), 187-201.

Kawulich, B. B. (2005). Participant observation as a data collection method, Vol. 6 (2) 28.

König, B., Diehl, K., Tscherning, K., \& Helming, K. (2013). A framework for structuring interdisciplinary research management. Research Policy, 42(1), 261-272. https://doi.org/10.1016/j.respol.2012.05.006.

Kuik, J. (2018). Table leaders facilitation. 2018, May 31.

Leslie, H., \& Storey, D. (2003). Entering the field. Development fieldwork edited by Scheyvens and storey. 6 Bonhill Street, London England EC2A 4PU United Kingdom: SAGE Publications Ltd119-138.

Lüdi, G. (2015). Monolingualism and multilingualism in the construction and dissemination of scientific knowledge. In U. Jessner, \& C. J. Kramsch (Eds.). The multilingual challenge: Cross-disciplinary perspectives (pp. 213-238). Berlin: De Gruyter Mouton.

Mackewn, J. (2008). Facilitation as action research in the moment. In P. Reason, \& H. Bradbury (Eds.). The SAGE handbook of action research (pp. 615-628). . https:// doi.org/10.4135/9781848607934.n54.

May, T., \& Perry, B. (2017). Reflexivity: The essential guide (1st ed.). Thousand Oaks, CA: SAGE Publications.

Mikkelsen, B. (2005). Methods for development work and research: A new guide for practitioners (2nd ed.). New Delhi; Thousand Oaks, Calif: SAGE Publications.

Mills, S. (1997). Discourse. London; New York: Routledge.

Nikulina, V., Baumann, H., Simon, D., \& Sprei, F. (2018). Sustainable transport futures: Analysis of the selected methodologies supporting the planning process towards achieving goal 11 sustainable cities and communities. Handbook of sustainability science and research473-488. https://doi.org/10.1007/978-3-319-63007-6_29.

Offermann, L., Matos, K., \& Basu DeGraaf, S. (2014). ¿Están hablando de mí?: Challenges for multilingual organizations. Journal of Managerial Psychology, 29(6), 644-660. https://doi.org/10.1108/JMP-10-2012-0315.

Perry, B., \& Atherton, M. (2017). Beyond critique: The value of co-production in realising just cities? Local Environment, 22(Suppl.1), 36-51. https://doi.org/10.1080/ 13549839.2017 .1297389$.

Pohl, C., Rist, S., Zimmermann, A., Fry, P., Gurung, G. S., Schneider, F., ... Wiesmann, U. (2010). Researchers' roles in knowledge co-production: Experience from sustainability research in Kenya, Switzerland, Bolivia and Nepal. Science \& Public Policy, 37(4), 267-281. https://doi.org/10.3152/030234210X496628.

Polk, M. (2015). Transdisciplinary co-production: Designing and testing a transdisciplinary research framework for societal problem solving. Futures, 65, 110-122. https://doi.org/10.1016/j.futures.2014.11.001.

Polk, M., \& Kain, J.-H. (2015). Co-producing knowledge for sustainable urban futures. Co-producing knowledge for sustainable cities: Joining forces for change. Abingdon, Oxon; New York, NY: Routledge1-22.

Reachable | Definition of reachable in English by Oxford Dictionaries. (n.d.). Retrieved 19 October 2018, from https://en.oxforddictionaries.com/definition/ reachable.

Robèrt, K.-H., Borén, S., Ny, H., \& Broman, G. (2017). A strategic approach to sustainable transport system development - part 1: Attempting a generic community planning process model. Journal of Cleaner Production, 140, 53-61. https://doi.org/10.1016/j.jclepro.2016.02.054.

Robertson, R. (2014). Globalisation or glocalisation? Globalizations, 11(4), 447-459. https://doi.org/10.1080/14747731.2014.951203.

Scheyvens, R. (Ed.). (2014). Development fieldwork: A practical guide(2nd ed.). Los Angeles: SAGE.

Schuttenberg, H. Z., \& Guth, H. K. (2015). Seeking our shared wisdom: A framework for understanding knowledge coproduction and coproductive capacities. Ecology and Society, 20(1), https://doi.org/10.5751/ES-07038-200115.

Simon, D. (Ed.). (2016). Rethinking sustainable cities: Accessible. green and fair: Policy Press.

Simon, D., McGregor, D., Nsiah-Gyabaah, K., \& Thompson, D. (2003). Poverty elimination, North-South research collaboration, and the politics of participatory development. Development in Practice, 13(1), 40-56. https://doi.org/10.1080/0961452022000037973.

Simon, D., Palmer, H., Riise, J., Smit, W., \& Valencia, S. (2018). The challenges of transdisciplinary knowledge production: From unilocal to comparative research. Environment and Urbanization. https://doi.org/10.1177/0956247818787177.

Snodgrass, A., \& Coyne, R. (1997). Is designing hermeneutical? Architectural Theory Review, 2(1), 65-97. https://doi.org/10.1080/13264829609478304.

Somerville, M. (2005). 'Working' culture: Exploring notions of workplace culture and learning at work. Pedagogy Culture and Society, 13(1), 5-26. https://doi.org/10. 1080/14681360500200212.

Sullivan, R. (2004). The challenges of interpreting multilingual. Multijural Legislation, 29(3), 985-1066.

Sundberg, G. (2013). Language policy and multilingual identity in sweden through the lens of generation Y. Scandinavian Studies, 85(2), 205. https://doi.org/10.5406/ scanstud.85.2.0205.

Taylor, C. (1994). The politics of recognition. In C. Taylor, \& A. Appiah (Eds.). Multiculturalism: Examining the politics of recognition. Edited and introduced by amy gutmann (pp. 25-73). Princeton: N.J: Princeton University Press.

Valadka, R. (2018). Table leaders facilitation. 2018, May 28.

Wälitalo, L. (2018). Multilingual group facilitation. 2018, March 20.

Waters, J. (2016). Accessible cities: From urban density to multidimensional accessibility. Rethinking sustainable cities: Accessible, green and fair. Policy Press11-60.

Weber, T. (2018). Language matters in transdisciplinarity (2018, October 2) Retrieved 4 October 2018, from Integration and Implementation Insights websitehttps:// i2insights.org/2018/10/02/language-matters/.

Wolniarska-Roszak, A. (2018). Table leaders facilitation. 2018, March 26.

Wright, S. (2011). Democracy, communities of communication and the European Union. In S. Adamo, \& A. Kjaer (Eds.). Linguistic diversity and European democracy (pp. 35-56). Aldershot: Ashgate Publishing Limited.

Wuelser, G., Pohl, C., \& Hirsch Hadorn, G. (2012). Structuring complexity for tailoring research contributions to sustainable development: A framework. Sustainability Science, 7(1), 81-93. https://doi.org/10.1007/s11625-011-0143-3.

Yanaprasart, P., \& Lüdi, G. (2017). Diversity and multilingual challenges in academic settings. International Journal of Bilingual Education and Bilingualism, 1-16. https://doi.org/10.1080/13670050.2017.1308311. 